\title{
Minimal residual disease monitoring in neuroblastoma patients based on the expression of a set of real-time RT-PCR markers in tumor-initiating cells
}

\author{
TRI BUDI HARTOMO ${ }^{1}$, AIKO KOZAKI ${ }^{3}$, DAIICHIRO HASEGAWA ${ }^{3}$, THI VAN HUYEN PHAM ${ }^{2}$, \\ NOBUYUKI YAMAMOTO ${ }^{2}$, ATSURO SAITOH ${ }^{3}$, TOSHIAKI ISHIDA ${ }^{3}$, KEIICHIRO KAWASAKI ${ }^{3}$, \\ YOSHIYUKI KOSAKA ${ }^{3}$, HIROKI OHASHI ${ }^{1}$, TOMOTO YAMAMOTO ${ }^{1,2}$, SATORU MORIKAWA $^{1,2}$, \\ SATOSHI HIRASE ${ }^{2}$, IKUKO KUBOKAWA ${ }^{2}$, TAKESHI MORI ${ }^{2}$, TOMOKO YANAI ${ }^{2}$, \\ AKIRA HAYAKAWA ${ }^{2}$, YASUHIRO TAKESHIMA ${ }^{2}$, KAZUMOTO IIJIMA ${ }^{2}$, \\ MASAFUMI MATSUO ${ }^{4}$, HISAHIDE NISHIO ${ }^{1,2}$ and NORIYUKI NISHIMURA ${ }^{1,2}$ \\ Departments of ${ }^{1}$ Epidemiology and ${ }^{2}$ Pediatrics, Kobe University Graduate School of Medicine; \\ ${ }^{3}$ Department of Hematology and Oncology, Kobe Children's Hospital; \\ ${ }^{4}$ Department of Medical Rehabilitation, Kobe Gakuin University, Kobe, Japan
}

Received December 3, 2012; Accepted December 28, 2012

DOI: $10.3892 / o r .2013 .2286$

\begin{abstract}
Minimal residual disease (MRD) is derived from tumor-initiating cells (TICs) and is responsible for tumor relapse. Neuroblastoma is characterized by extreme tumor heterogeneity, and more than half of high-risk patients experience tumor relapse. To overcome tumor heterogeneity and achieve more sensitive detection of MRD, several sets of real-time RT-PCR markers have been reported for MRD monitoring in neuroblastoma patients from different centers. However, these markers vary across centers and are still being validated. In the present study, we validated the ability of 14 commonly used real-time RT-PCR markers to detect MRD based on their expression in neuroblastoma TICs, and we developed a novel MRD detection protocol, which scored the samples as MRD-positive when the expression of one of the 11 real-time RT-PCR markers (CHRNA3, CRMP1, DBH, DCX, DDC, GABRB3, GAP43, ISL1, KIF1A, PHOX2B and $\mathrm{TH})$ exceeded the normal range. By using this protocol, we prospectively monitored MRD in 73 bone marrow (BM), 12 peripheral blood stem cell and 8 peripheral blood samples from 14 neuroblastoma patients treated at a single center. We scored 100, 56, 56 and 57\% BM cytology-positive, elevated vanillylmandelic acid (VMA), elevated homovanillic acid (HVA) and elevated neuron-specific enolase (NSE) samples as
\end{abstract}

Correspondence to: Dr Noriyuki Nishimura, Departments of Pediatrics and Epidemiology, Kobe University Graduate School of Medicine, 7-5-1 Kusunoki-cho, Chuo-ku, Kobe 650-0017, Japan E-mail: nnishi@med.kobe-u.ac.jp

Key words: minimal residual disease, neuroblastoma, tumor-initiating cells, real-time reverse transcription-polymerase chain reaction
MRD-positive, respectively. MRD was also positive in 48, 45, 46 and $43 \%$ of the BM cytology-negative and normal VMA, normal HVA and normal NSE samples, respectively. These results suggest that the present MRD detection protocol based on the expression of a set of 11 real-time RT-PCR markers in neuroblastoma TICs achieves sensitive MRD monitoring in neuroblastoma patients.

\section{Introduction}

Neuroblastoma is one of the most common solid tumors in children and accounts for $\sim 15 \%$ of pediatric cancer-related deaths $(1,2)$. Neuroblastoma cells originate from neural crest cells that are committed to the development of the sympathetic nervous system, and display extreme heterogeneity ranging from spontaneous regression to malignant progression. Although the prognosis for neuroblastoma patients has improved considerably, $<40 \%$ of high-risk patients can expect long-term survival (3). The majority of cancer-related deaths in neuroblastoma are due to tumor relapse caused by minimal residual disease (MRD).

Tumor-initiating cells (TICs) account for only a small population of tumor cells that generate the bulk of the tumor through continuous self-renewal and differentiation, and are found in a variety of cancers (4-6). TICs can persist as MRD locally in the primary tumor or distantly in the blood, bone marrow and metastatic organs $(7,8)$. Neuroblastoma TICs were recently identified as spheres grown in serum-free nonadherent culture and were shown to express stem cell markers, exhibit self-renewal, and form metastatic tumors in immunodeficient mice $(9,10)$.

Sensitive detection of MRD is fundamental when monitoring the disease status and evaluating the treatment response $(7,11)$. In acute lymphoblastic leukemia (ALL), MRD detection with real-time PCR is directed against tumor-specific junctions using 
genomic DNA as a template. This sensitive MRD detection in ALL patients has revealed the most important prognostic factors and is used to stratify treatments in the clinic (12-14). In neuroblastoma, the rationale for introducing the current MRD detection protocols to stratify treatments in the clinic remains unclear $(15,16)$. Since no recurrent fusion genes have been found in neuroblastoma cells, MRD detection in neuroblastoma patients requires well-defined real-time RT-PCR markers that can be assessed using cDNA as a template. Although ideal MRD markers should be exclusively expressed in neuroblastoma cells and not in normal cells, commonly used markers are selected by their ability to experimentally define a cut-off value that distinguishes neuroblastoma cells from normal cells.

Tyrosine hydroxylase (TH) was initially evaluated as a single marker for neuroblastoma MRD detection, but was hampered by its expression in normal cells (17-20). Pairedlike homeobox 2b (PHOX2B) was subsequently identified as a more specific single marker, but was not highly expressed in all neuroblastoma tumors (21). To overcome tumor heterogeneity and achieve more sensitive detection of MRD in neuroblastoma patients, several sets of multiple markers have been reported at different centers. Based on gene expression analyses in neuroblastoma tumors, Viprey et al (22) identified the following three markers: doublecortin (DCX), PHOX2B and $\mathrm{TH}$, while Cheung et al (23) independently identified the following 8 markers: cyclin D1 (CCND1), collapsin response mediator protein 1 (CRMP1), dopa decarboxylase (DDC), GABA A receptor $\beta 3$ (GABRB3), ISL LIM homeobox 1 (ISL1), kinesin family member 1A (KIF1A), PHOX2B, and transforming acidic coiled-coil containing protein 2 (TACC2). Furthermore, Stutterheim et al (24) selected the following 6 markers: cholinergic receptor, nicotinic, $\alpha 3$ (CHRNA3), dopamine $\beta$-hydroxylase (DBH), DDC, growth-associated protein 43 (GAP43), PHOX2B and TH. These MRD markers are currently being validated.

In the present study, we validated 14 commonly used real-time RT-PCR markers based on their expression in neuroblastoma TICs, and developed a novel MRD detection protocol. By using this protocol, we prospectively monitored MRD in 73 bone marrow (BM), 12 peripheral blood stem cell (PBSC), and 8 peripheral blood (PB) samples from 14 neuroblastoma patients treated at Kobe Children's Hospital, Japan, between November, 2010 and August, 2012.

\section{Materials and methods}

Patients and samples. Normal PB samples were obtained from three healthy volunteers. PB, PBSC and BM samples were obtained from 14 neuroblastoma patients who were treated at Kobe Children's Hospital between November, 2010 and August, 2012. Written informed consent was obtained from the patients, and the study was approved by Kobe Children's Hospital Ethics Board. The samples were handled in accordance with the Guidelines for the Clinical Research of Kobe University Graduate School of Medicine. All PB, PBSC and BM samples were separated using Mono-Poly Resolving Medium (DS Pharma Biomedical, Osaka, Japan), and nucleated cells were collected according to the manufacturer's instructions.
Neuroblastoma TICs. Human neuroblastoma BE(2)-C cells were obtained from the American Type Culture Collection (Manassas, VA, USA), and neuroblastoma TICs were isolated as spheres of $\mathrm{BE}(2)-\mathrm{C}$ cells as described previously (25). Briefly, $\mathrm{BE}(2)-\mathrm{C}$ cells were cultured at $37^{\circ} \mathrm{C}\left(5 \% \mathrm{CO}_{2}\right.$ and 95\% air) in sphere medium consisting of Dulbecco's modified Eagle's medium (DMEM)/Ham's F12 (3:1) (Wako Pure Chemical-Industries, Osaka, Japan), $100 \mathrm{U} / \mathrm{ml}$ penicillin/streptomycin (PC/SM) (Invitrogen), 2\% B27 supplement (Life Technologies, Carlsbad, CA, USA), $40 \mathrm{ng} / \mathrm{ml}$ basic fibroblast growth factor (bFGF) (R\&D Systems, Minneapolis, MN, USA) and $20 \mathrm{ng} / \mathrm{ml}$ epidermal growth factor (EGF) (R\&D Systems). The cells were subcultured with non-enzymatic cell dissociation solution (Sigma, St. Louis, MO, USA) and maintained for more than 4 weeks in Ultra-Low Attachment culture dishes (Corning, Inc., Corning, NY, USA).

RNA extraction and cDNA synthesis. Total RNA from normal BM was obtained from Clonetech (Palo Alto, CA, USA). Total RNA from neuroblastoma TICs as well as PB, PBSC and BM samples was extracted with a TRIzol Plus RNA Purification kit (Life Technologies) according to the manufacturer's instructions. RNA integrity was evaluated by agarose gel electrophoresis. cDNA was synthesized from 1 (or 0.5 ) $\mu \mathrm{g}$ of total RNA using a Quantitect Reverse Transcription kit (Qiagen, Valencia, CA, USA) and diluted to a total volume of 80 (or 40) $\mu 1$.

Real-time RT-PCR. Real-time RT-PCR was performed using an ABI 7500 Fast Real-time PCR system (Applied Biosystems, Foster City, CA, USA) in a total volume of $15 \mu \mathrm{l}$ consisting of $7.5 \mu \mathrm{l}$ of $2 \mathrm{X}$ FastStart Universal SYBR-Green Master (Roche, Mannheim, Germany), $1.5 \mu \mathrm{l}$ each of $3 \mu \mathrm{M}$ sense and antisense primers, and $1 \mu \mathrm{l}$ of the sample cDNA (corresponding to $12.5 \mathrm{ng}$ of total RNA). Each cDNA was amplified with a precycling hold at $95^{\circ} \mathrm{C}$ for $10 \mathrm{~min}$, followed by 40 cycles at $95^{\circ} \mathrm{C}$ for $15 \mathrm{sec}$ and $60^{\circ} \mathrm{C}$ for $60 \mathrm{sec}$, and one cycle at $95^{\circ} \mathrm{C}$ for $15 \mathrm{sec}$, $60^{\circ} \mathrm{C}$ for $60 \mathrm{sec}, 95^{\circ} \mathrm{C}$ for $15 \mathrm{sec}$ and $60^{\circ} \mathrm{C}$ for $15 \mathrm{sec}$. Each sample was analyzed in triplicate. To correct for differences in the amount of total RNA and in the efficiency of cDNA synthesis, the expression of each marker was calculated based on the relative standard curve method using $\beta 2$-microglobulin (B2M) as an endogenous reference for normalization.

Primers. The following primers were used: GD2 synthase (B4GALNT1, NM_001478) 5'-CCAACTCAACAGGCAA CTACAA-3' (sense) and 5'-ATGTCCCTCGGTGGAG AAC-3' (antisense); CCND1 (NM_053056) 5'-GAAGATCGTCGC CACCTG-3' (sense) and 5'-GACCTCCTCCTCGCACTTC T-3' (antisense); CHRNA3 (NM_000743) 5'-TGAAATGGAACC CCTCTGAC-3' (sense) and 5'-GGAAATCCCCAACAGC ATT-3' (antisense); CRMP1 (NM_001014809) 5'-GAGTGC AGCCGACATCATC-3' (sense) and 5'-GGGCTCTCCA AAAACTAGGG-3' (antisense); DBH (NM_000787) 5'-GAC CCCAAGGATTACCTCATT-3' (sense) and 5'-GTTGATGGC CTCCAGTGAC-3' (antisense); DCX (NM_000555) 5'-CAT CCCCAACACCTCAGAAG-3' (sense) and 5'-GGAGGTTCC GTTTGCTGA-3' (antisense); DDC (NM_000790) 5'-GGA GAAGGGGGAGGAGTG-3' (sense) and 5'-CAGCCGATG GATCACTTTG-3' (antisense); GABRB3 (NM_000814) 
Table I. Expression profile of real-time RT-PCR markers in neuroblastoma TICs.

\begin{tabular}{lccc}
\hline Gene name & $\begin{array}{c}\text { Normal PB } \\
\left(\text { mean }_{\mathrm{T}} \pm \mathrm{SD}\right)\end{array}$ & $\begin{array}{c}\text { Normal BM } \\
\left(\text { mean }_{\mathrm{T}} \pm \mathrm{SD}\right)\end{array}$ & $\begin{array}{c}\text { Neuroblastoma TICs } \\
\left(\mathrm{mean}_{\mathrm{T}} \pm \mathrm{SD}\right)\end{array}$ \\
\hline B4GALNT1 & $>40$ & $31.593 \pm 0.382$ & $25.535 \pm 0.122$ \\
CCND1 & $34.051 \pm 0.329$ & $28.725 \pm 0.096$ & $22.243 \pm 0.056$ \\
CHRNA3 & $>40$ & $31.028 \pm 0.709$ & $21.538 \pm 0.102$ \\
CRMP1 & $>40$ & $34.863 \pm 0.957$ & $21.779 \pm 0.103$ \\
DBH & $>40$ & $>40$ & $23.133 \pm 0.059$ \\
DCX & $>40$ & $31.683 \pm 0.727$ & $22.037 \pm 0.544$ \\
DDC & $>40$ & $36.150 \pm 0.329$ & $21.538 \pm 0.102$ \\
GABRB3 & $35.996 \pm 0.130$ & $31.952 \pm 0.865$ & $22.340 \pm 0.102$ \\
GAP43 & $35.639 \pm 0.922$ & $31.828 \pm 0.920$ & $19.777 \pm 0.010$ \\
ISL1 & $>40$ & $>40$ & $24.929 \pm 0.044$ \\
KIF1A & $>40$ & $32.601 \pm 0.728$ & $19.901 \pm 0.044$ \\
PHOX2B & $>40$ & $>40$ & $20.351 \pm 0.140$ \\
TACC2 & $>40$ & $28.007 \pm 1.272$ & $34.782 \pm 0.001$ \\
TH & $>40$ & $32.741 \pm 1.224$ & $18.666 \pm 0.034$ \\
\hline
\end{tabular}

PB, peripheral blood; BM, bone marrow; TICs, tumor-initiating cells. B4GALNT1. $\beta-1,4$ N-acetylgalactosaminyltransferase 1; CCND1, cyclin D1; CHRNA3, cholinergic receptor, nicotinic, $\alpha 3$; CRMP1, collapsin response mediator protein 1; DBH, dopamine $\beta$-hydroxylase; DCX, doublecortin; DDC, dopa decarboxylase; GABRB3, GABA A receptor $\beta 3$; GAP43, growth-associated protein 43; ISL1, ISL LIM homeobox 1; KIF1A, kinesin family member 1A; PHOX2B, paired-like homeobox 2b; TACC2, transforming acidic coiled-coil containing protein 2; TH, tyrosine hydroxylase.

5'-GGGTGTCCTTCTGGATCAATTA-3' (sense) and 5'-TTG TCAGCACAGTTGTGATCC-3' (antisense); GAP43 (NM_001130064) 5'-GAGGATGCTGCTGCCAAG-3' (sense) and 5'-GGCACTTTCCTTAGGTTTGGT-3' (antisense); ISL1 (NM_002202) 5'-AAGGACAAGAAGCGAAGCAT-3' (sense) and 5'-TTCCTGTCATCCCCTGGATA-3' (antisense); KIF1A (NM_004321) 5'-CTTGGCGACATCACTGACAT-3' (sense) and 5'-GCT GGACAGGGCTGAGAG-3' (antisense); PHOX2B (NM_003924) 5'-CTACCCCGACATCTACACTCG-3' (sense) and 5'-CCTGCTTGCGAAACTTGG-3' (antisense); TACC2 (NM_006997) 5'-CCCCACTATTCGCTCAGAAA-3' (sense) and 5'-GGGCTTCTATCCGCATGAT-3' (antisense); TH (NM_199292) 5'-GCCAAGGACAAGCTCAGG-3' (sense) and 5'-AGCGTGTACGGGTCGAACT-3' (antisense); and 32-microglobulin (B2M, NM_004048) 5'-TTCTGGCCTG GAGGCTATC-3' (sense) and 5'-TCAGGAAATTTGACTT TCCATTC-3' (antisense).

Standard curves. To mimic MRD-positive PB, PBSC and BM samples, total RNA from neuroblastoma TICs was serially diluted into total RNA from normal PB to yield a total amount of $1.0 \mu \mathrm{g}$. The resulting six-step 5-fold dilutions were converted to cDNA yielding 100, 20, 4, 0.8, 0.16 and $0.032 \%$ dilutions. To obtain a standard curve, the $\mathrm{C}_{\mathrm{T}}$ values for each marker were obtained from triplicate real-time RT-PCR and plotted against the logarithm of the $\%$ dilution/100. Due to slight expression of each marker in normal PB, we generated standard curves with $\mathrm{R}^{2}>0.90$ for each marker by limiting the plotted points of the $\%$ dilution. The quantitative range was defined as the minimum $\%$ dilution that plotted to the standard curve or above.
Normal range. Based on the threshold defined by the European Study Group on MRD detection in ALL (ESG-MRD-ALL), the mean $C_{T}$ value of a normal sample -3 was set as the maximum $\mathrm{C}_{\mathrm{T}}$ value for the normal sample (12). The normal range was then defined as any value less than the $\%$ dilution of MRD that corresponded to the maximum $\mathrm{C}_{\mathrm{T}}$ value of the normal sample. If the mean $\mathrm{C}_{\mathrm{T}}$ value of the normal sample was $>40$, the normal range was defined as less than the $\%$ dilution of MRD that corresponded to the minimum \% dilution of MRD in the quantitative range.

\section{Results}

Expression profile of real-time RT-PCR markers in neuroblastoma TICs. To achieve more sensitive detection of MRD, we first analyzed the expression of commonly used real-time RT-PCR markers in normal PB, normal BM and neuroblastoma TICs that were isolated as spheres of $\mathrm{BE}(2)-\mathrm{C}$ cells (25). In addition to the 13 MRD markers that were collectively reported by Viprey et al (22), Cheung et al (23) and Stutterheim et al (24), a well-examined MRD marker, B4GALNT1, was also included in the present study (26). When the expression of these 14 MRD markers were analyzed by real-time RT-PCR, CHRNA3, CRMP1, DBH, DCX, DDC, GABRB3, GAP43, ISL1, KIF1A, PHOX2B and TH were predominantly expressed in neuroblastoma TICs in which the mean $C_{T}$ value was $>9.0$ lower when compared with that in normal $\mathrm{PB}$ and $\mathrm{BM}$ (Table I). Considering the variation of the mean $\mathrm{C}_{\mathrm{T}}$ value for normal $\mathrm{PB}, \mathrm{BM}$ and neuroblastoma TICs (12), B4GALNT1, CCND1 and TACC2 were excluded from the present study. 
Table II. Normal range of real-time RT-PCR markers.

\begin{tabular}{lccccc}
\hline Gene name & \multicolumn{1}{c}{ Standard curve } & $\mathrm{R}^{2}$ & Quantitative range (\%) & $\begin{array}{c}\text { Normal range } \\
\text { in PB/PBSC (\%) }\end{array}$ & $\begin{array}{c}\text { Normal range } \\
\text { in BM }(\%)\end{array}$ \\
\hline CHRNA3 & $\mathrm{C}_{\mathrm{T}}=-3.69 \log (\%$ dilution/100) +22.28 & 0.969 & $\geq 0.032$ & $<0.032$ & $<0.413$ \\
CRMP1 & $\mathrm{C}_{\mathrm{T}}=-3.04 \log (\%$ dilution$/ 100)+26.21$ & 0.911 & $\geq 0.032$ & $<0.032$ & $<0.207$ \\
DBH & $\mathrm{C}_{\mathrm{T}}=-3.66 \log (\%$ dilution $/ 100)+26.60$ & 0.946 & $\geq 0.032$ & $<0.032$ & $<0.032$ \\
DCX & $\mathrm{C}_{\mathrm{T}}=-3.0 \log (\%$ dilution $/ 100)+27.39$ & 0.912 & $\geq 0.160$ & $<0.160$ & $<5.598$ \\
DDC & $\mathrm{C}_{\mathrm{T}}=-3.71 \log (\%$ dilution $/ 100)+23.99$ & 0.983 & $\geq 0.032$ & $<0.032$ & $<0.051$ \\
GABRB3 & $\mathrm{C}_{\mathrm{T}}=-3.43 \log (\%$ dilution $/ 100)+25.00$ & 0.948 & $\geq 0.032$ & $<0.032$ & $<1.059$ \\
GAP43 & $\mathrm{C}_{\mathrm{T}}=-3.34 \log (\%$ dilution $/ 100)+24.37$ & 0.966 & $\geq 0.032$ & $<0.032$ & $<0.694$ \\
ISL1 & $\mathrm{C}_{\mathrm{T}}=-3.71 \log (\%$ dilution $/ 100)+25.36$ & 0.985 & $\geq 0.160$ & $<0.160$ & $<0.160$ \\
KIF1A & $\mathrm{C}_{\mathrm{T}}=-4.40 \log (\%$ dilution $/ 100)+22.43$ & 0.962 & $\geq 0.032$ & $<0.032$ & $<0.351$ \\
PHOX2B & $\mathrm{C}_{\mathrm{T}}=-4.19 \log (\%$ dilution $/ 100)+23.46$ & 0.944 & $\geq 0.032$ & $<0.032$ & $<0.032$ \\
TH & $\mathrm{C}_{\mathrm{T}}=-3.78 \log (\%$ dilution/100) +22.13 & 0.987 & $\geq 0.160$ & $<0.160$ & $<0.160$ \\
\hline
\end{tabular}

CHRNA3, cholinergic receptor, nicotinic, $\alpha 3$; CRMP1, collapsin response mediator protein 1; DBH, dopamine $\beta$-hydroxylase; DCX, doublecortin; DDC, dopa decarboxylase; GABRB3, GABA A receptor $\beta 3$; GAP43, growth-associated protein 43; ISL1, ISL LIM homeobox 1; KIF1A, kinesin family member 1A; PHOX2B, paired-like homeobox 2b; TH, tyrosine hydroxylase.

Standard curves for real-time RT-PCR markers. To mimic the actual expression of neuroblastoma MRD markers in clinical samples as precisely as possible, we generated their standard curves by serially diluting neuroblastoma TICs into normal PB. The 11 MRD markers (CHRNA3, CRMP1, DBH, DCX, DDC, GABRB3, GAP43, ISL1, KIF1A, PHOX2B and TH) were amplified by real-time RT-PCR, and triplicate $\mathrm{C}_{\mathrm{T}}$ values for each MRD marker were plotted against the logarithm of the $\%$ dilution/100. Although the standard curve for the real-time RT-PCR assay should theoretically have $\mathrm{R}^{2}>0.99$, the actual $R^{2}$ value is lower than expected due to slight expression in normal PB. In the present study, we generated the standard curve with $\mathrm{R}^{2}>0.90$ by limiting the plotted points of the $\%$ dilution (Table II). Accordingly, 5 points (100, 20, 4, 0.8 and $0.16 \%$ dilution) were plotted against triplicate $\mathrm{C}_{\mathrm{T}}$ values for DCX, ISL1 and TH (Fig. 1). For CHRNA3, CRMP1, DBH, DDC, GABRB3, GAP43, KIF1A and PHOX2B, 6 points (100, $20,4,0.8,0.16$ and $0.032 \%$ dilution) were used (Fig. 1).

Normal range of real-time RT-PCR markers. Although the quantitative range frequently reflects the portion of the standard curve in which the MRD levels can be accurately quantitated, we here defined the quantitative range as the minimum $\%$ dilution that was plotted to the standard curve or above. While DCX, ISL1 and TH had a quantitative range of $\geq 0.160 \%$ dilution, the quantitative range of CHRNA3, CRMP1, DBH, DDC, GABRB3, GAP43, KIF1A and PHOX2B was $\geq 0.032 \%$ dilution (Table II). To account for tumor heterogeneity, we set the maximum $\mathrm{C}_{\mathrm{T}}$ value for the $\mathrm{PB} / \mathrm{PBSC}$ and $\mathrm{BM}$ samples as the mean $\mathrm{C}_{\mathrm{T}}$ value of the normal $\mathrm{PB}$ and $\mathrm{BM}$ cells -3 , respectively, according to the threshold defined by ESG-MRD-ALL (12). The normal range for each MRD marker in the PB/PBSC and $\mathrm{BM}$ samples was then defined as less than the \% dilution that corresponded to the maximum $\mathrm{C}_{\mathrm{T}}$ value for the $\mathrm{PB} / \mathrm{PBSC}$ and $\mathrm{BM}$ samples, respectively. If the mean $\mathrm{C}_{\mathrm{T}}$ value in normal $\mathrm{PB}$ and $\mathrm{BM}$ cells was $>40$, the normal range was defined as less than the $\%$ dilution that corresponded to the minimum \% dilu- tion in the quantitative range. For the PB samples, the normal ranges of all MRD markers did not exceed the minimum $\%$ dilution in the quantitative range (Table II). For the BM samples, the normal ranges of DBH, ISL1, PHOX2B and TH did not exceed the minimum \% dilution in the quantitative range, whereas the normal ranges of CHRNA3, CRMP1, DCX, DDC, GABRB3, GAP43 and KIF1A were determined to be $<0.413,<0.207,<5.598,<0.051,<1.059,<0.694$ and $<0.351 \%$, respectively (Table II).

MRD sample characteristics. All 93 MRD samples were obtained from 14 neuroblastoma patients (\#1-14) who were prospectively treated at Kobe Children's Hospital between November, 2010 and August, 2012. Patients \#1-10 developed primary tumors and were treated according to the Japan Neuroblastoma Study Group (JNBSG) protocol. Low-risk patient \#1 was subjected to surgical therapy followed by watchful waiting. Low-risk patient \#2 was treated with one course of the LI-A regimen $\left(1.5 \mathrm{mg} / \mathrm{m}^{2} \mathrm{VCR}\right.$ and $\left.300 \mathrm{mg} / \mathrm{m}^{2} \mathrm{CPA}\right)$. Intermediate-risk patient \#3 was treated with one course of the LI-D regimen $\left(1.5 \mathrm{mg} / \mathrm{m}^{2} \mathrm{VCR}\right.$, $900 \mathrm{mg} / \mathrm{m}^{2} \mathrm{CPA}, 30 \mathrm{mg} / \mathrm{m}^{2}$ THP and $60 \mathrm{mg} / \mathrm{m}^{2}$ CDDP). High-risk patient \#4 was treated with five courses of the 05A3 regimen $\left(2,400 \mathrm{mg} / \mathrm{m}^{2} \mathrm{CPA}, 1.5 \mathrm{mg} / \mathrm{m}^{2} \mathrm{VCR}, 40 \mathrm{mg} / \mathrm{m}^{2}\right.$ THP and $100 \mathrm{mg} / \mathrm{m}^{2}$ CDDP) followed by peripheral blood stem cell transplantation (PBSCT), radiation therapy and surgical therapy. High-risk patient \#5 was treated with five courses of the 05A3 regimen followed by PBSCT and radiation therapy. High-risk patient \#6 was treated with one course of the 05A1 regimen $\left(1,200 \mathrm{mg} / \mathrm{m}^{2} \mathrm{CPA}, 1.5 \mathrm{mg} / \mathrm{m}^{2} \mathrm{VCR}\right.$, $40 \mathrm{mg} / \mathrm{m}^{2} \mathrm{THP}$ and $100 \mathrm{mg} / \mathrm{m}^{2} \mathrm{CDDP}$ ) and four courses of the $05 \mathrm{~A} 3$ regimen followed by PBSCT, radiation therapy and surgical therapy. High-risk patient \#7 was treated with one course of the $05 \mathrm{~A} 1$ regimen and four courses of the $05 \mathrm{~A} 3$ regimen followed by PBSCT and radiation therapy. High-risk patient \#8 was treated with one course of the 05A1 regimen and four courses of the $05 \mathrm{~A} 3$ regimen. High-risk patients \#9 

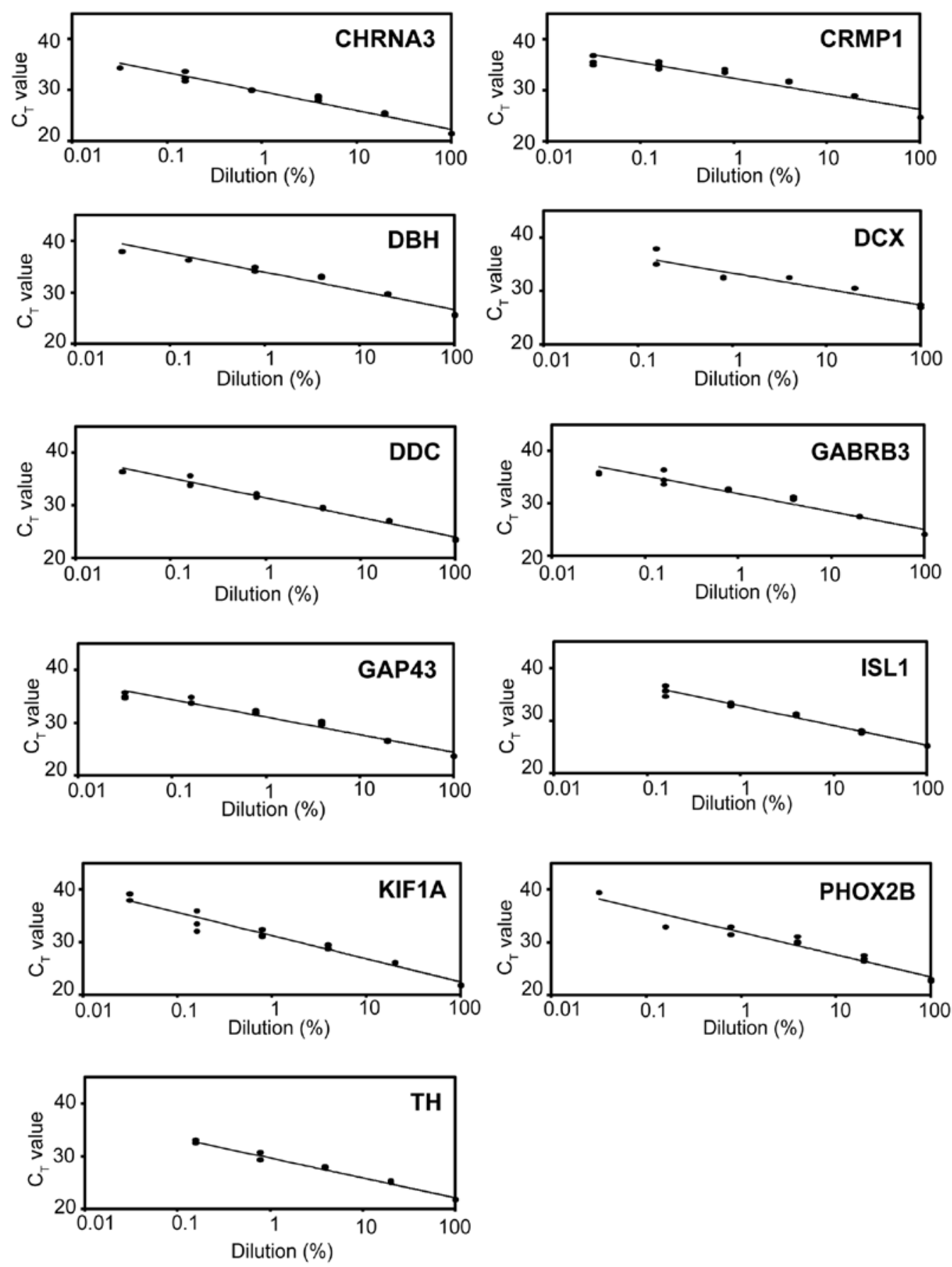

Figure 1. Standard curves for real-time RT-PCR markers. Triplicate $\mathrm{C}_{\mathrm{T}}$ values for CHRNA3, CRMP1, DBH, DCX, DDC, GABRB3, GAP43, ISL1, KIF1A, PHOX2B and TH were plotted against the logarithm of the \% dilution/100.

and 10 were treated with one course of the $05 \mathrm{~A} 1$ regimen and three courses of the 05A3 regimen. Patients \#11-14 experienced tumor relapses and were subjected to salvage chemotherapy. Patient \#11 had one course of the IREC regimen $\left(300 \mathrm{mg} / \mathrm{m}^{2}\right.$ CPT-11, $300 \mathrm{mg} / \mathrm{m}^{2} \mathrm{VP}-16,240 \mathrm{mg} / \mathrm{m}^{2}$ CBDCA) and five courses of the topotecan/CPA regimen $\left(3.75 \mathrm{mg} / \mathrm{m}^{2}\right.$ topotecan, $\left.1,250 \mathrm{mg} / \mathrm{m}^{2} \mathrm{CPA}\right)$. Patient \#12 had three courses of the ICE regimen $\left(6,000 \mathrm{mg} / \mathrm{m}^{2} \mathrm{IFO}, 800 \mathrm{mg} / \mathrm{m}^{2}\right.$ CBDCA, $500 \mathrm{mg} / \mathrm{m}^{2}$ VP-16) and two courses of the CPT-11 regimen $\left(125 \mathrm{mg} / \mathrm{m}^{2}\right.$ CPT-11) followed by bone marrow transplantation (BMT). Patient \#13 had two courses of the CPT-11 regimen, six courses of IREC regimen, five courses of the topotecan/CPA regimen, and three courses of the topotecan/TMZ regimen $\left(3.75 \mathrm{mg} / \mathrm{m}^{2}\right.$ topotecan, $750 \mathrm{mg} / \mathrm{m}^{2} \mathrm{TMZ}$ ). Patient \#14 had three courses of the ICE regimen and two courses of the IREC regimen. All patients were subjected to MRD sampling as frequently as possible during the course of treatment (Fig. 2).

Expression profile of real-time RT-PCR markers in MRD samples. CHRNA3, CRMP1, DBH, DCX, DDC, GABRB3, GAP43, ISL1, KIF1A, PHOX2B and TH expression was determined by real-time RT-PCR in the 93 MRD (73 BM, 12 PBSC and $8 \mathrm{~PB}$ ) samples. Each marker was scored as positive when its expression exceeded the normal range. The number of 


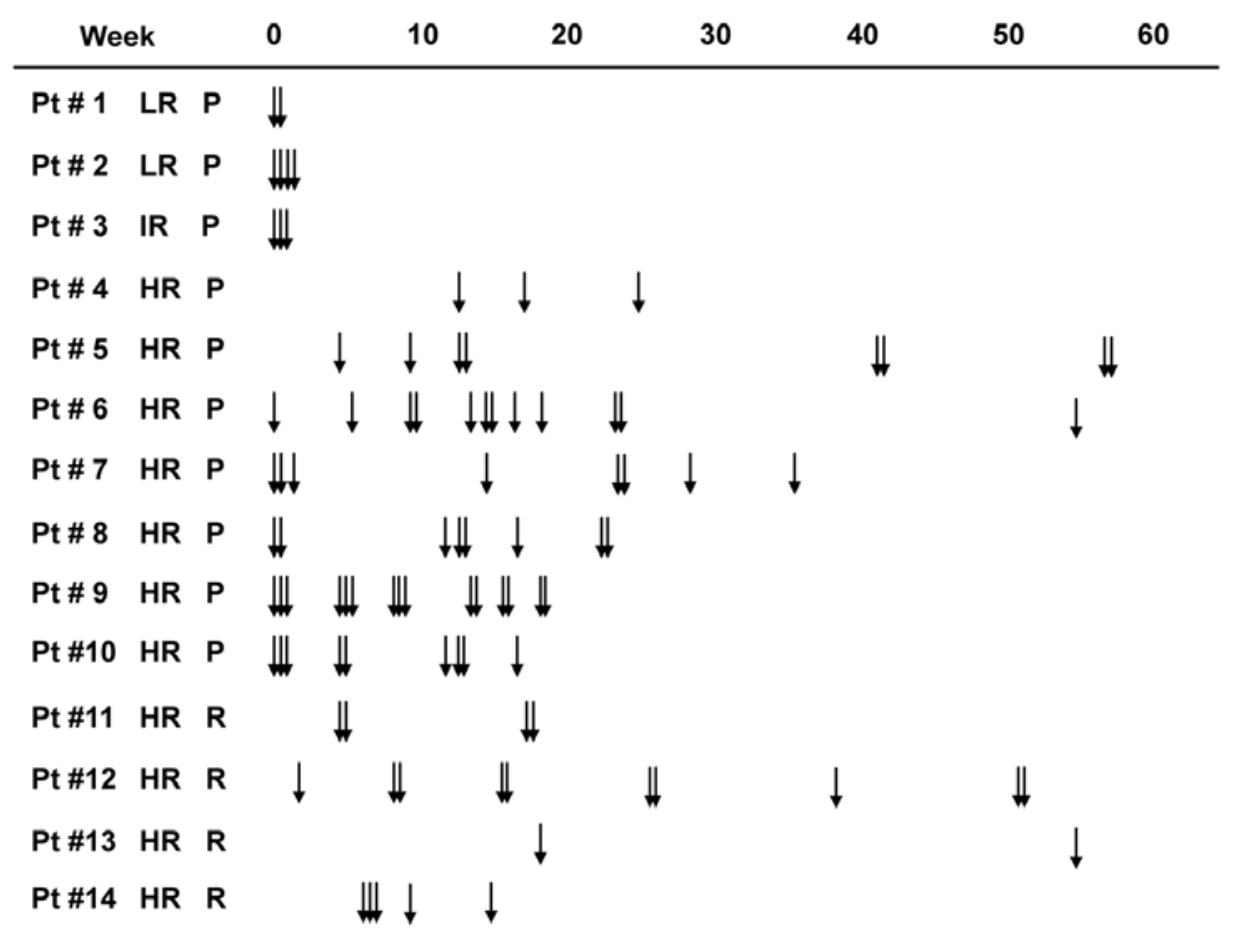

Figure 2. MRD sample characteristics. Downward arrows indicate the time points of MRD sampling. Week 0 was defined as the time when the primary or recurrent tumor was diagnosed. Pt, patient. LR, low-risk; IR, intermediate-risk; HR, high-risk. P, primary tumor; R, recurrent tumor.

positive samples for each marker varied from 4 (GABRB3) to 33 (PHOX2B). PHOX2B and DBH seemed to be sensitive markers in the present BM samples (Table III). Although only a limited number of PBSC and PB samples were analyzed, the sensitivity of each marker also varied between the BM, PBSC and PB samples as described previously (24). Only KIF1A, DCX, CRMP1 and GABRB3 were able to detect MRD in the present PBSC and PB samples (Table III).

Comparison of the present MRD detection protocol with clinical examinations. To validate the applicability of a set of these 11 commonly used real-time RT-PCR markers to monitor MRD, we compared these results with BM cytology, urinary vanillylmandelic acid (VMA), urinary homovanillic acid (HVA) and serum neuron-specific enolase (NSE) data. BM cytology data were obtained from 73 MRD (73 BM) samples, whereas urinary VMA, urinary HVA, and serum NSE data were obtained from 89 MRD (71 BM, 10 PBSC, and 8 PB) samples (Table IV). MRD was scored as positive when the expression of one of the 11 markers exceeded the normal range. Thus, 100, 56, 56 and 57\% of BM cytology-positive $(\mathrm{n}=10)$, elevated VMA ( $>15 \mu \mathrm{g} / \mathrm{mg} \mathrm{Cr}, \mathrm{n}=45)$, elevated HVA $(>30 \mu \mathrm{g} / \mathrm{mg} \mathrm{Cr}, \mathrm{n}=43$ ), and elevated NSE ( $>20 \mathrm{ng} / \mathrm{ml}, \mathrm{n}=49)$ samples were MRD-positive, respectively (Table IV). MRD was also positive in $48,45,46$ and $43 \%$ of BM cytologynegative ( $\mathrm{n}=63$ ), normal VMA ( $\leq 15 \mu \mathrm{g} / \mathrm{mg} \mathrm{Cr}, \mathrm{n}=44)$, normal HVA $(\leq 30 \mu \mathrm{g} / \mathrm{mg} \mathrm{Cr}, \mathrm{n}=46)$, and normal NSE $(\leq 20 \mathrm{ng} / \mathrm{ml}$, $\mathrm{n}=40$ ) samples, respectively (Table IV). As BM samples were obtained from at least two sites (left and right iliac crests), we also compared real-time RT-PCR results from the paired BM samples. Of the 23 pairs of BM cytology-negative samples, 11 pairs were MRD-positive at only one site. The remaining
12 pairs had identical results for both sites; 6 pairs were MRD-negative and 6 pairs MRD-positive.

\section{Discussion}

In the present study, we validated the ability of 14 commonly used real-time RT-PCR markers to detect neuroblastoma MRD based on their expression in neuroblastoma TICs. We then developed a novel MRD detection protocol and prospectively monitored MRD in 73 BM, 12 PBSC and 8 PB samples from 14 neuroblastoma patients treated at Kobe Children's Hospital between November, 2010 and August, 2012. Compared to currently used protocols, our protocol had two advantages. First, it determined 11 real-time RT-PCR markers based on their expression in neuroblastoma TICs. Second, it calculated the expression of these markers using the relative standard curve method and scored their expression levels as \% dilution.

Several sets of real-time RT-PCR markers have been reported for MRD monitoring in neuroblastoma patients. Neuroblastoma is characterized by extreme heterogeneity that is observed in three levels: i) between different patients, ii) between different tumors within a patient, and iii) between different cells within a tumor. Regarding the heterogeneity between different patients, highly variable expression of CHRNA3, DBH, DDC, GAP43, PHOX2B and TH was detected in tumor samples from 56 patients (24). In terms of the heterogeneity between different tumors within a patient, one of the 5 MRD markers (CHRNA3, DDC, GAP43, PHOX2B and TH) showed a $>10$-fold difference in relative expression in 6 out of 56 pairs of BM samples obtained from two different sites (27). Regarding heterogeneity between different cells within a tumor, Stutterheim et al (27) recently reported that GAP43 and 
Table III. Expression profile of real-time RT-PCR markers in MRD samples.

\begin{tabular}{|c|c|c|c|}
\hline & BM sample & PBSC sample & PB sample \\
\hline \multicolumn{4}{|l|}{ CHRNA3 } \\
\hline Positive & 10 & 0 & 0 \\
\hline Negative & 63 & 12 & 8 \\
\hline \multicolumn{4}{|l|}{ CRMP1 } \\
\hline Positive & 14 & 0 & 1 \\
\hline Negative & 59 & 12 & 7 \\
\hline \multicolumn{4}{|l|}{$\mathrm{DBH}$} \\
\hline Positive & 22 & 0 & 0 \\
\hline Negative & 51 & 12 & 8 \\
\hline \multicolumn{4}{|l|}{ DCX } \\
\hline Positive & 9 & 0 & 2 \\
\hline Negative & 64 & 12 & 6 \\
\hline \multicolumn{4}{|l|}{ DDC } \\
\hline Positive & 14 & 0 & 0 \\
\hline Negative & 59 & 12 & 8 \\
\hline \multicolumn{4}{|l|}{ GABRB3 } \\
\hline Positive & 3 & 0 & 1 \\
\hline Negative & 70 & 12 & 7 \\
\hline \multicolumn{4}{|l|}{ GAP43 } \\
\hline Positive & 9 & 0 & 0 \\
\hline Negative & 64 & 12 & 8 \\
\hline \multicolumn{4}{|l|}{ ISL1 } \\
\hline Positive & 14 & 0 & 0 \\
\hline Negative & 55 & 11 & 7 \\
\hline \multicolumn{4}{|l|}{ KIF1A } \\
\hline Positive & 11 & 2 & 1 \\
\hline Negative & 62 & 10 & 7 \\
\hline \multicolumn{4}{|l|}{ PHOX2B } \\
\hline Positive & 33 & 0 & 0 \\
\hline Negative & 40 & 12 & 8 \\
\hline \multicolumn{4}{|l|}{$\mathrm{TH}$} \\
\hline Positive & 12 & 0 & 0 \\
\hline Negative & 61 & 12 & 8 \\
\hline
\end{tabular}

MRD, minimal residual disease; BM, bone marrow; PBSC, peripheral blood stem cell; PB, peripheral blood; CHRNA3, cholinergic receptor, nicotinic, $\alpha 3$; CRMP1, collapsin response mediator protein 1 ; DBH, dopamine $\beta$-hydroxylase; DCX, doublecortin; DDC, dopa decarboxylase; GABRB3, GABA A receptor $\beta 3$; GAP43, growth-associated protein 43; ISL1, ISL LIM homeobox 1; KIF1A, kinesin family member 1A; PHOX2B, paired-like homeobox 2b; TH, tyrosine hydroxylase.

TH expression differed by $>10 \mathrm{C}_{\mathrm{T}}$ values across subclones of the same neuroblastoma IMR-32 cells isolated by serial dilution. Due to the differential gene expression between whole tumor cells and TICs $(9,25)$, we validated MRD markers based
Table IV. Comparison of the present MRD detection protocol with clinical examinations.

\begin{tabular}{lcc}
\hline & $\begin{array}{c}\text { MRD } \\
\text { Positive }\end{array}$ & $\begin{array}{c}\text { MRD } \\
\text { Negative }\end{array}$ \\
\hline $\begin{array}{l}\text { BM cytology } \\
\text { Positive }\end{array}$ & 0 \\
Negative & 10 & 33 \\
Urinary VMA & 30 & \\
$>15 \mu \mathrm{g} / \mathrm{mg} \mathrm{Cr}$ & & 20 \\
$\leq 15 \mu \mathrm{g} / \mathrm{mg} \mathrm{Cr}$ & 25 & 24 \\
Urinary HVA & 20 & \\
$>30 \mu \mathrm{g} / \mathrm{mg} \mathrm{Cr}$ & & 19 \\
$\leq 30 \mu \mathrm{g} / \mathrm{mg} \mathrm{Cr}$ & 24 & 25 \\
Serum NSE & 21 & 21 \\
$>20 \mathrm{ng} / \mathrm{ml}$ & & 23 \\
$\leq 20 \mathrm{ng} / \mathrm{ml}$ & 28 & \\
\hline
\end{tabular}

MRD, minimal residual disease; BM, bone marrow; VMA, vanillylmandelic acid; HVA, homovanillic acid; NSE, neuron-specific enolase.

on their expression in neuroblastoma TICs instead of whole neuroblastoma cells used by previous studies. Accordingly, B4GALNT1, CCND1 and TACC2 were determined to be inappropriate MRD markers, even though they were selected by their ability to experimentally define a cut-off value with which to distinguish neuroblastoma cells from normal cells in previous studies $(23,26)$.

Although most previous studies determined the expression of MRD markers by real-time RT-PCR using the comparative $\mathrm{C}_{\mathrm{T}}$ method, we hypothesized that standard curves generated by serially diluting neuroblastoma TICs into normal PB would reflect more accurate MRD marker expression in clinical samples. Therefore, we calculated MRD marker expression by the relative standard curve method and scored it as the $\%$ dilution. While previous studies recommended a set of 3 , 6 or 8 markers by which to detect MRD in neuroblastoma patients (22-24), we used a set of 11 MRD markers (CHRNA3, CRMP1, DBH, DCX, DDC, GABRB3, GAP43, ISL1, KIF1A, PHOX2B and TH). PHOX2B was the most sensitive MRD marker in the present BM samples. Among 40 PHOX2Bnegative $\mathrm{BM}$ samples, only 7 samples were positive for CRMP1, DBH, DDC, ISL1 and/or TH. Although CRMP1, DCX, GABRB3 and KIF1A were not as sensitive as PHOX2B in the BM samples, they were able to detect MRD in the present PB and PBSC samples. Consequently, a set of these 11 markers was able to detect MRD in more than $40 \%$ of the BM cytologynegative, normal urinary VMA, normal urinary HVA and normal serum NSE samples analyzed in the present study.

In summary, the present MRD detection protocol based on the expression of a set of 11 real-time RT-PCR markers (CHRNA3, CRMP1, DBH, DCX, DDC, GABRB3, GAP43, ISL1, KIF1A, PHOX2B and TH) in neuroblastoma TICs achieved sensitive MRD monitoring in neuroblastoma patients who were prospectively treated at a single center. 


\section{Acknowledgements}

This study was supported in part by the Grants-in-Aid for the Scientific Research from the Ministry of Education, Culture, Sports, Science and Technology of Japan, and grants from the Showa-hokokai, the Hyogo Prefecture Health Promotion Association, the Foundation for Promotion of Cancer Research, and the Hyogo Medical Association.

\section{References}

1. Brodeur GM: Neuroblastoma: biological insights into a clinical enigma. Nat Rev Cancer 3: 203-216, 2003.

2. Maris JM, Hogarty MD, Bagatell R and Cohn SL: Neuroblastoma. Lancet 369: 2106-2120, 2007.

3. Maris JM: Recent advances in neuroblastoma. N Engl J Med 362: 2202-2211, 2010

4. Jordan CT, Guzman ML and Noble M: Cancer stem cells. N Engl J Med 355: 1253-1261, 2006.

5. Visvader JE and Lindeman GJ: Cancer stem cells in solid tumours: accumulating evidence and unresolved questions. Nat Rev Cancer 8: 755-768, 2008.

6. Vermeulen L, de Sousa e Melo F, Richel DJ and Medema JP: The developing cancer stem-cell model: clinical challenges and opportunities. Lancet Oncol 13: e83-e89, 2012.

7. Müller V, Alix-Panabières C and Pantel K: Insights into minimal residual disease in cancer patients: implications for anti-cancer therapies. Eur J Cancer 46: 1189-1197, 2010.

8. Mordant P, Loriot Y, Lahon B, et al: Minimal residual disease in solid neoplasia: new frontier or red-herring? Cancer Treat Rev 38: 101-110, 2012

9. Hansford LM, McKee AE, Zhang L, et al: Neuroblastoma cells isolated from bone marrow metastases contain a naturally enriched tumor-initiating cell. Cancer Res 67: 11234-11243, 2007.

10. Coulon A, Flahaut M, Mühlethaler-Mottet A, et al: Functional sphere profiling reveals the complexity of neuroblastoma tumorinitiating cell model. Neoplasia 13: 991-1004, 2011.

11. Lin H, Balic M, Zheng S, Datar R and Cote RJ: Disseminated and circulating tumor cells: role in effective cancer management. Crit Rev Oncol Hematol 77: 1-11, 2011.

12. van der Velden VHJ, Cazzaniga G, Schrauder A, et al: Analysis of minimal residual disease by Ig/TCR gene rearrangements: guidelines for interpretation of real-time quantitative PCR data. Leukemia 21: 604-611, 2007.

13. Flohr T, Schrauder A, Cazzaniga G, et al: Minimal residual disease-directed risk stratification using real-time quantitative PCR analysis of immunoglobulin and T-cell receptor gene rearrangements in the international multicenter trial AIEOP-BFM ALL 2000 for childhood acute lymphoblastic leukemia. Leukemia 22: 771-782, 2008.
14. Kågedal B: Detecting minimal residual disease in neuroblastoma: still a ways to go. Clin Chem 55: 1268-1270, 2009.

15. Stutterheim J, Zappeij-Kannegieter L, Versteeg R, Caron HN, van der Schoot CE and Tytgat GAM: The prognostic value of fast molecular response of marrow disease in patients aged over 1 year with stage 4 neuroblastoma. Eur J Cancer 47: 1193-1202, 2011.

16. Yáñez Y, Grau E, Oltra S, et al: Minimal disease detection in peripheral blood and bone marrow from patients with non-metastatic neuroblastoma. J Cancer Res Clin Oncol 137: 1263-1272, 2011.

17. Burchill SA, Bradbury FM, Smith B, Lewis IJ and Selby P: Neuroblastoma cell detection by reverse transcriptase-polymerase chain reaction (RT-PCR) for tyrosine hydroxylase mRNA. Int J Cancer 57: 671-675, 1994.

18. Miyajima Y, Kato K, Numata SI, Kudo K and Horibe K: Detection of neuroblastoma cells in bone marrow and peripheral blood at diagnosis by the reverse transcriptase-polymerase chain reaction for tyrosine hydroxylase mRNA. Cancer 75: 2757-2761, 1995.

19. Kuçi Z, Seitz G, Kuçi S, et al: Pitfalls in detection of contaminating neuroblastoma cells by tyrosine hydroxylase RT-PCR due to catecholamine-producing hematopoietic cells. Anticancer Res 26: 2075-2080, 2006.

20. Viprey VF, Corrias MV, Kågedal B, et al: Standardisation of operating procedures for the detection of minimal disease by QRT-PCR in children with neuroblastoma: quality assurance on behalf of SIOPEN-R-NET. Eur J Cancer 43: 341-350, 2007.

21. Stutterheim J, Gerritsen A,Zappeij-Kannegieter L, et al: PHOX2B is a novel and specific marker for minimal residual disease testing in neuroblastoma. J Clin Oncol 26: 5443-5449, 2008.

22. Viprey VF, Lastowska MA, Corrias MV, Swerts K, Jackson MS and Burchill SA: Minimal disease monitoring by QRT-PCR: guidelines for identification and systematic validation of molecular markers prior to evaluation in prospective clinical trials. J Pathol 216: 245-252, 2008.

23. Cheung IY, Feng Y, Gerald W and Cheung NK: Exploiting gene expression profiling to identify novel minimal residual disease markers of neuroblastoma. Clin Cancer Res 14: 7020-7027, 2008.

24. Stutterheim J, Gerritsen A, Zappeij-Kannegieter L, et al: Detecting minimal residual disease in neuroblastoma: the superiority of a panel of real-time quantitative PCR markers. Clin Chem 55: 1316-1326, 2009.

25. Nishimura N, Hartomo TB, Pham TVH, et al: Epigallocatechin gallate inhibits sphere formation of neuroblastoma BE(2)-C cells Environ Health Prev Med 17: 246-251, 2012.

26. Cheung IY and Cheung NK: Quantitation of marrow disease in neuroblastoma by real-time reverse transcription-PCR. Clin Cancer Res 7: 1698-1705, 2001.

27. Stutterheim J, Zappeij-Kannegieter L, Ora I, et al: Stability of PCR targets for monitoring minimal residual disease in neuroblastoma. J Mol Diagn 14: 168-175, 2012. 